\title{
Potato Cooperation: Lessons of the History for Modern Development
}

\author{
Vladimir Osipov ${ }^{12 *}$, Vadim Evseev ${ }^{3}$, and Tatiana Skryl $^{3}$ \\ ${ }^{1}$ MGIMO University, 119454, Vernadskogo Avenue, 76, Moscow, Russia \\ ${ }^{2}$ Lorch Potato Research Institute, 140051, Lorkha str., 23, letter B, Kraskovo village, Moscow \\ Region, Russia \\ ${ }^{3}$ Plekhanov Russian University of Economics, 115054, Stremyanny lane, 36, Moscow, Russia
}

\begin{abstract}
The article offers a discussion about finding solutions to uneven market power of potato producers and its processors. The high market power of persons not directly related to potato production has a direct impact on the income level of those who produce the product. The obvious injustice of this situation is not the know-how of the current stage of development of economic relations in Russia, but a wellforgotten old, unresolved issue from the past. This situation, when the manufacturer of the product found himself in a deliberately subordinate position with respect to the buyer, wholesale processor, breeder, is completely new. And the solution that previously yielded a positive result cannot be called new - this is production cooperation. There are institutional conditions for its implementation, and it seems that economic conditions have matured to strengthen agricultural producers. The aim of the paper is to compare the market power of the before Revolution situation in agriculture and post-Soviet situation of modern agroeconomic development. Results. The compare of the market power shows that in the market economy there is almost unaltered structure of the food market and unbalanced power distribution with tilt for the seller but not producer. Methods. There were methods of institutional analysis, historical, normative, comparative and some others used in frame of research. Results. Market power of sellers in the past and modern time plays negative role on reproduction process. As it is shown on potato production, only cooperatives can solve the problem of unbalanced market power distribution and will make producers more competitive in reproduction process. The methodology of institutional analysis and specially historical institutionalism help us to understand the market power distribution mechanism in reproduction process. It makes our research useful for agrarian policy makers on all levels of power.
\end{abstract}

\section{Introduction}

* Corresponding author: vs.ossipov@gmail.com 
Many authors note that agricultural policy contributes to the formation of a strategy for increasing the efficiency of agricultural production. We should mention the works of E.N. Krylatykh, A.G. Zeldner, A.G. Paptsov, I.G. Ushachev and many others. The problems of a cooperative solution to the problems of reducing the market power of processors are considered in the works: A.V. Chayanov, N.D. Kondratyev, I.N. Buzdalov, G.I.Shmelev, A.N. Chelintsev, E.S. Ephroimsky and others.

Protecting the economic interests of agricultural market actors is becoming an urgent necessity due to the protectionist policies of foreign countries and the confident anticompetitive behavior of foreign agricultural producers. The unfavorable external environment in terms of uncompetitive market behavior, weighed down by sanctions, forces us to introduce protectionist measures to protect the domestic market and domestic producers.

\section{Methods of research}

The internal architecture of the agricultural and food market also does not contribute to the development of production.

Using the methodology of historical institutionalism, we are able to assess the negative repeatability of monopolization processes in agriculture. Famous scientist A.V. Chayanov noted: "Repeating the stages of development of industrial capitalism, agriculture, emerging from the forms of semi-subsistence existence, falls under the power of commercial capitalism, which sometimes in the form of very large trading enterprises draws into its sphere of influence the masses of dispersed peasant farms and, having mastered the ties of these small producers with market, economically subordinates them to its influence and, developing a system of bonded credit, turns the organization of agricultural production into almost a special kind of distribution process, built on the "sweating system"" (Chayanov, 1966). Turning to materials on the history of potato cooperation, we can observe the following picture. Potato consumption in the first third of the twentieth century mainly occurred in the manufacturing economy, however, the need for marketing surplus increased. Private potato production is most prevalent in Kostroma, Yaroslavl, Vladimir, Ryazan, Tula and Nizhny Novgorod provinces. Here, in connection with a large harvest of potatoes, potato processing plants also arose.

\section{Research results}

The increase in potato harvesting has made processing plants regional monopolies for the reception of raw materials. Potatoes were processed mainly into starch and molasses. The monopolistic position of potato processing plants increased their market power over the power of potato producers, which resulted in the latter becoming dependent on the former. Potato growers understood the profitability of their market position and made wide use of it, abusing their monopoly position with impunity and forcing potato harvesters to become addicted. So, the acceptance prices for potatoes were usually set at a very low level. In addition, a whole system of measuring, weighing and all kinds of discounts was introduced, as well as delays in receiving potatoes and paying for them. Payment of potatoes by goods at prices higher than market prices by $30-40 \%$ (sugar, flour, tobacco, etc.) was also practiced. Interestingly, the main disaster for the potato producer was not a bad harvest, but a rich one. The higher the yield, the lower prices fell and the more pressure the breeders increased on producers. A special method of enriching processors was the incorrect (fraudulent) acceptance of potatoes. So, a measure equal to 
four, artificially increased by a hoop stuffed from above on the edge, as if to prevent the potatoes from falling out. Due to this hoop, the quadrangle artificially increased. The surplus in this case reached from $1 / 4$ to $3 / 4$ measures. Also practiced the reception of potatoes with the top. Such actions leveled the measure of the quadruple and increased it to $11 / 8-11 / 16$ of the legal quadruple. In those days when there were especially many distributors, the factories offered to accept potatoes for bribes of 2-3 quadruples from carts of 24 fours (from 15 to 18\%). Dissenting producers could bring potatoes back. Clearly, there were none. On measuring, on weighing, on deceiving producers, breeders made big fortunes, while manufacturers suffered more and more. It should be noted that the breeders' market power was almost undivided in relation to small producers, while large producers had the opportunity to use normal sales conditions, both in terms of the size of the four, and in measurements and body kits. Long-term preservation of this trend squeezed small producers out of the market and preferred large ones. This was not limited to the disasters of small producers. After all, they still had to get money for the surrendered potatoes. Having handed over the potatoes, he did not know the price at which he would be calculated. The explanation for this situation was the ignorance of the price that the owner of raw starch would receive when sending it to the plant. It was from this price that prices were determined further along the production chain. Thus, only some time after the start of the delivery of potatoes to the grate factory, the peasants knew the price, payment for which they began to receive even later, and the final payment was made by the owner of the plant after 4-6 months, making partial payments in small amounts during this period.

The time delay in calculating and splitting up the amounts due to the producer for the potatoes delivered to the plant also made sense to the breeder, which forced the population to pay for the delivered potatoes not money, but goods at inflated prices.

Formally, the peasant could demand payment in cash, but under the reigning market power of the processor, this would only lead to the fact that the next time potatoes would be delivered even more difficult, then it was possible before. The peasant was forced to take expensive goods in payment for potatoes. Overpayments for goods "sold" in this way ranged from 30 to $50 \%$ of the average market price. The waiting period for cash in payment for the delivered potatoes stretched from 3 to 5 months.

\section{Discussion}

This state of affairs did not suit, first of all, the peasantry itself, and the most active of them, thought about organizing their own sales. So began the potato cooperation.

The beginning of potato cooperation was laid by the foundation of the first potato cooperative in 1909 in the village of Shunga, Kostroma province. 


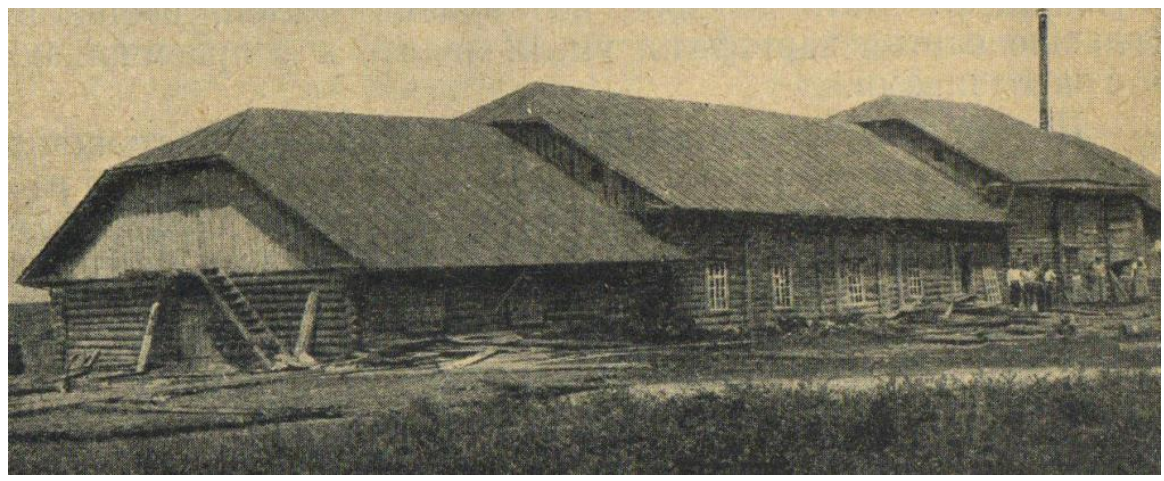

Fig. 1. Russia's first cooperative potato plant in the Kostroma province, built near the village of Shunga in 1909

Verkhovsky N.I. notes that starch and potato production are young but firmly established branches of large industry (Verkhovsky, 1912). He notes that they received the greatest distribution in the volosts of Chernozavodskaya, Shungenskaya, Koryakovskaya and Klimovskaya - 22 potato plants are represented here, of which 6 belong to cooperatives.

Obviously, at first the cooperative movement met with resistance from private enterprises: there were cases of re-buying equipment that was supposed to go to the cooperative factory, soldering workers of the cooperative factory and campaigning against the cooperative movement. Since the construction of the cooperative plant required funds, private enterprises also took advantage of this, lending them funds under enslaving conditions. Despite all the obstacles, by 1911 in the Kostroma province 4 cooperative potato processing plants had already been built, and by 1912 there were already 6 of them.

The development of potato cooperation and processing of raw materials led to the fact that on July 05, 1917, under the auspices of the Provisional Government, an All-Russian Congress of starch-and-breeder breeders was convened, and on 01-02 August 1917, a Congress of potato-breeders was convened, and at the last it was decided to unite into the All-Russian society of starch-syrup-breeders "Vokpaz". The October Revolution and subsequent decrees on the nationalization of land and enterprises ceased to exist in Vokpaz, but the very fact of the self-organization of industry enterprises under the influence of market forces and with the aim of coordinating activities within the industry is important. Perhaps, the development of rules of conduct for participants in the market would allow discarding the most discriminatory practices in activity, which would give an additional impetus to the development of the industry.

One cannot but recall one of the most important principles of the cooperative movement put forward by V.A. Huber: "Cooperation does not threaten the law, no one's fair interest. It does not require any advantages for itself, no help "(Efroimsky, 1929). It is important to note here the independence and self-organization of the cooperative movement in the interests of the producers of the product and its consumers, because the removal of a chain of intermediaries reduces the price of the final product.

The second wave of cooperation in potato growing and its processing began already in 1918 with the organization of Soyuzkartofel. In April-May 1918, its constituent assembly was held in Moscow. In connection with the abolition of private ownership of the means of production, all cooperative starch plants were merged into the All-Russian Union of Potatoes. So, about 80 plants entered the union; their work was coordinated by the union, 
and the products were centrally sent to Glavkrahmal, which combined the entire starch and syrup industry of the country. In certain periods, Soyuzkartofel provided up to $75 \%$ of the work of Glavkrahmal. In June 1920, Soyuzkartofel included consumer cooperation and received a monopoly on both production and marketing of products.

In recent history, approximately the same picture is observed. Agricultural producers often prefer to sell products "from the field". Despite the fact that property rights have been realized in one way or another, either through property shares and land shares during the privatization of collective farms and state farms, or through direct purchase of land and means of production on the free market, the problem of monopoly and high transaction costs did not allow the formation of a self-organizing infrastructure a market in which agricultural producers could freely and profitably sell their products, and buyers receive high-quality food. Why it happens? Agricultural producers and consumers of their products are at rather large distances from each other, and also in time, raw materials and semi-finished products go through several operations of the production process to obtain the finished product. The market infrastructure has changed significantly, new participants in the reproduction process have been added, but one problem has remained the same - the level of transaction costs for the agricultural producer has remained quite high, which does not allow them to play the role of an active participant in the food market. The high level of transaction costs is due to two reasons: the geographical and temporal disunity of the producer and the consumer, which leads to transport costs, as well as storage costs, but at the same time, the costs of organizing sales channels play a role - wholesale and retail business. In addition, processing of agricultural raw materials and product packaging is important. In sum, these costs turn out to be unbearable for the agricultural producer, which forces him to take a passive part in the reproduction process and to sell products "from the field" at a rather low price. An agricultural producer has a choice of ways to sell his goods. If he sells products directly to the consumer, he can get a good price, but he must spend time and make efforts (invest labor) to sell them, at the same time carry out production at the enterprise. Another way of the product is "from the farm gate": it is bought by intermediaries who perform the functions of storage, transportation, part-time processing, packaging at the right time and in the right place for the consumer.

The marketing effectiveness of agricultural raw materials and products, thus, determines how far agriculture is integrated into the reproductive process. If sales receive a large share of the profits from the sale of finished products, then the role of agricultural production as an actor in the reproduction process is extremely weak. In this situation, market power is more in the hands of the sales sector, and it dictates the conditions for the functioning of markets for all other participants - both producers of agricultural raw materials and products, and end-users of products (Bogoviz et al., 2018).

In these conditions, it also depends on the marketing firms what prices are set for the producer of raw materials and for the consumer of the final product with a given offer and given demand for agricultural products. In developed countries, the food market is quite developed and is regulated not only by the laws of the market, but also by regulations. It is completely wrong to assume that the law can establish prices for products, but it is possible to create such institutional conditions for all participants in the reproduction process that production is advisable in all operations of the reproduction process. Currently, it is necessary to note the imbalance in the rate of profit in different operations of the reproduction process, when some participants have a very high level, while others balance on the verge of profitability. It is important to note that this situation is not only abnormal from the point of view of market relations, but also from the standpoint of food security, since an imbalance makes the production of products of domestic origin difficult 
and, as it was not so long ago, leads to the dominance of imports, as sales firms are interested in guaranteed and large deliveries, which underdeveloped agriculture cannot provide. Chayanov A.V. described the marketing process of agricultural products: "In the course of studying the structure of the trading apparatus for the markets for various agricultural products, we can note five main stages of the commodity path of agricultural products:

I. Goods sprayed by individual manufacturers are collected by a number of buyers and prasols and concentrated in their hands.

II. The goods collected by buyers are subjected to rough sorting and transported from assembly sites to local wholesale centers.

III. In wholesale centers, the goods are sorted and distributed according to the directions of further movement.

IV. Collected and sorted goods are transported to local consumer wholesale centers.

V. From the local wholesale centers, the goods are delivered to the distributor by means of a commercial distribution apparatus (local shopkeepers and other traders)."

N.D. Kondratiev noted that the cooperative movement is undoubtedly a vital movement. This is supported by both theory and practice (Kondratyev, 1915). With the exception of some features and modern technologies, the architecture of the agricultural market has changed little over almost a century of history. This is evidence of the rootedness of such a marketing institution for the agricultural market. This means that there are forces that support such a market structure and the level of market power of the participants in the reproduction process. It is impossible to recognize such a structure as effective due to the imbalance of interests and the rate of profit among participants in the reproductive process. Although the imbalance of the profit margin in operations within the value chain is characteristic of any production process, nevertheless, it is in the agrarian sector and food supply that it is most sensitive to consumers and producers of agricultural raw materials.

As we noted earlier, the normative establishment of a pricing process instead of a market one is unacceptable, since it will undermine the effectiveness of the entire reproduction process and reduce the tax base, so efforts should be made to find institutions that can indirectly influence the distribution of profits within the value chain from obtaining raw materials to bringing the finished product to the final consumer.

Indirect influence can be exerted by strengthening market power of the weakest participant in the reproductive process - producers of agricultural raw materials and primary products (Zeldner, 2005).

It should be noted that in order to increase the efficiency of collective farms, they were restructured and decollectivized, as a result of which, as conceived by the reformers, a layer of effective farmers, producers of agricultural products, should have formed (Tillack and Schultze, 2001). At the same time, the authors make an important reservation: "The implementation of privatization programs does not necessarily contribute to improving the efficiency of management." The main misconception lies in the belief that the economy of the capitalist market will arise spontaneously as soon as private ownership is established, free prices are introduced, the monetary system is stabilized, and unregulated, competitive markets are created (Kregel et al., 1992). German experience shows a solution to the problem when agricultural producers - farmers, as the weakest participants in the reproduction process, were able to strengthen their role by forming cooperatives. Reproduction process operations, which are characterized by the combination of material resource flows, can be transferred for execution to cooperatives, the participation of agricultural producers in which allows them to gain greater market power by providing large volumes of standardized products in an understandable and 
predictable time frame. So, Bavarian farmers receive from the cooperatives seed material, fertilizers, machinery, young animals for growing, etc., carry out the production process in strict accordance with the technology, the implementation of which is carried out by specialists of the cooperative. At certain times, farmers turn in products to a cooperative, which provides not only the collection, but also the processing of raw materials at their own processing plants. Cooperatives allow farmers to strengthen their market power by participating in the management of neighboring operations of the production process. Some cooperatives turn out to be the main shareholders of processing enterprises and retail chains, which strengthens their market power even more, and the process of profit distribution makes it more fair and interesting for producers of agricultural raw materials. It should be noted that the European agricultural policy is based on subsidies to producer prices for the implementation of the completed production program, however, for our case this reason can be neglected, since we are only interested in the institutional structure that allows us to achieve a more balanced distribution of profits between participants in the reproduction process.

Such a model of relations between participants in the reproductive process in the agricultural sector would be quite applicable for the markets of the SCO countries, if not for one limitation - a low level of trust of actors to each other. It may seem that this is a purely Russian problem, however, it is not. The British historian J. Hosking notes: "The Western world is in a crisis of confidence" (Hosking, 2014). He talks about the loss of citizens' confidence in their states. The explanation of this phenomenon is beyond the scope of our study; therefore, we will not touch upon it, but only take it for granted (Hosking, 2010). Thus, trust is the cornerstone for strengthening the role of weak participants in the agricultural market for equalizing and more equitable balance of profits and ensuring food security. Professor R. Locke states: "Trust can be created! (Locke, 2001). " The formation of trust in the agricultural sector is quite possible, although at first glance the path to achievement is not entirely clear. We will try to form a direction of increasing confidence for the agricultural market.

\section{Conclusion}

The basic stage of the mechanism to increase confidence in the agricultural market is the interest of actors. Without actors' interest in building confidence, it is impossible to move on. Trust can become interesting if the institutional foundations in the agricultural market prove to be stable, in which the state and its bodies responsible for implementing the agricultural policy should show their interest, and more broadly, the bodies responsible for economic policy. Actors quickly respond to the stabilization of institutional conditions by expanding business activity, investments and capital investments. The second stage of the mechanism is realized through the active role of state policy in implementing institutional reforms. Here, public-private partnership projects that have proven their effectiveness in infrastructure projects will be most in demand. The promotion of cooperation and self-government (at least by the example of German unions of producers of various types of agricultural products), as well as highlighting their initiatives to the forefront in the process of developing the institutional conditions of the agricultural market, in essence, will help align market rules and self-control. The highest point of the confidence-building mechanism for the agricultural market is infrastructure. We have in mind the infrastructure of the market for agricultural products, which is formed subject to the confidence of the actors in relation to each other. Confidence undermining should be punished by expelling the agricultural producer from the union, wide dissemination of 
information about his unfair behavior in the market and the risks of interacting with such an actor.

\section{References}

1. A.V. Bogoviz, Y.A. Bugai, V.S. Osipov, Advances in Intelligent Systems and Computing, 622, 7-43 (2018)

2. A. Chayanov, The Theory of Peasant Economy. The American Economic Association. (1966)

3. E.S. Efroimsky, Agricultural cooperation in the system of monopoly capitalism (Kharkov: State Publishing House of Ukraine,1929)

4. G. Hosking, Trust: Money, Markets and Society (Seagull Books, 2010)

5. G. Hosking, Trust: a History (Oxford: Oxford University Press, 2014)

6. N.D. Kondratiev, Development of the economy of the Kineshem zemstvo of the Kostroma province (Socio-economic and financial essay) (Kineshma, 1915)

7. J. Kregel, E. Matzner, G. Graber, Market shock. International Institute of the World, 126 (1992)

8. R. Locke, Building Trust. Paper presented at the Annual Meetings of the American Political Science Association (San Francisco, 2001)

9. V. Osipov, S. Zhevora, N. Yanushkina, IOP Conference Series: Earth and Environmental Science, 274, conference 1 (2019)

10. N.G. Sidorova, V.S. Osipov, A.G. Zeldner, Import Substitution in Agriculture: Crises of Overproduction, Choice of Institutional Policy, Application of Behavioral Economics (2020). In: D. Solovev (eds) Smart Technologies and Innovations in Design for Control of Technological Processes and Objects: Economy and Production. FarEastCon. Smart Innovation, Systems and Technologies, 138, (Springer, Cham, 2018)

11. T. Skryl, V. Osipov, T. Vorozheikina, IOP Conference Series: Earth and Environmental Science, 274, conference 1 (2019).

12.P. Tillack, E. Schultze, Institutional problems of agricultural production. Agrifood complex of Russia on the market way. Analytical center of agrifood economics, Institute of transition economics (2001)

13. N.E. Verkhovsky, Dirt roads of the Kostroma province. Statistical study of 1912 (1912)

14. A. Zeldner, International Agricultural Journal, 5, 19-20, (2005) 